\title{
The Design and Evaluation of DACADE Visual Tool: Theoretical Implications
}

\author{
Madihah Sheikh Abdul Aziz ${ }^{1}$, Gitte Lindgaard ${ }^{2}$, Mohd Syarqawy Hamzah ${ }^{3}$, T.W. Allan Whitfield ${ }^{4}$ \\ ${ }^{1,3}$ Faculty of Information \& Communication Technology, International Islamic University Malaysia, Malaysia \\ ${ }^{2,4}$ School of Health, Art and Design, Swinburne University of Technology, Melbourne, Australia
}

\begin{tabular}{l}
\hline Article Info \\
\hline Article history: \\
Received Nov 27, 2017 \\
Revised Jan 28, 2018 \\
Accepted Feb 11, 2018 \\
\hline
\end{tabular}

Keywords:

Data analysis

Data collection

Theoretical implications

Visual tool

\begin{abstract}
A goal of every designer is to create successful products for consumers. In creating a successful product, it is crucial for a designer to understand consumers' perceptions of a product early in the design process. Nevertheless, design students lack the necessary data collection and user testing skills to support effective design decision-making. Consequently, their products might not be acceptable to the intended consumers and are thus likely to fail in the marketplace. For design students to acquire those skills, design curricula should incorporate statistical courses teaching the concepts of data and user testing. We addressed this challenge by developing an automated visual tool named DACADE, assisting design students to systematically collect and analyze data. This paper reports the theoretical implications discovered during the process from designing through to implementing and evaluating DACADE concerning the transfer of learning, the appropriateness of graphics used in a software tool, and user motivation in a learning environment.
\end{abstract}

Copyright $\odot 2018$ Institute of Advanced Engineering and Science. All rights reserved.

\section{Corresponding Author:}

Madihah Sheikh Abdul Aziz,

Department of Information Systems, Kuliyyah of ICT,

International Islamic University Malaysia,

Jalan Gombak, 53100, Gombak, Selangor, Malaysia

Email: madihahs@iium.edu.my

\section{INTRODUCTION}

A goal of every designer is to be successful in designing and developing products for his or her intended consumers. In order to be successful, as well as focusing on the objective requirements of a product, a designer should also consider consumers' subjective requirements [1]. It is also important for a designer to understand consumers' perception of a product early in the design process. This has increasingly been recognised as a serious concern for design students and novice designers who need to compete in the 21 st Century and become successful designers. One way for designers to ensure that consumers' perceptions and ideas are taken into account is to gather data from the target audiences of their proposed products and then to analyse those data statistically.

In our preliminary investigation, 20 design students and 10 design lecturers were interviewed; an email survey and archival search involving 51 universities that offer design courses in Asia, Australia, Europe and North America were carried out. The results suggested that both design students and lecturers were familiar only with some qualitative data collection methods but not with quantitative methods. The results also discovered that design students might benefit from a visual and interactive method to assist them in collecting and analyzing $\mathrm{z}$

As a remedy, we proposed DACADE: an automated visual tool for design students to systematically collect and analyze data. Prior to designing DACADE, we first reviewed the relevant theoretical frameworks to guide this research as summarized in the next section. 


\section{THEORETICAL IMPLICATIONS}

\subsection{Schema Theory}

Schemata refer to the internal models of the world learned through experience and stored in the brain; they are primarily applied to predict future events but also to interpret situations as they occur [2]. Any new concept, idea or information can become meaningful when they can be related to existing knowledge that someone already possesses [3]. Schemata are exclusive to each individual [4]. There will be no two people storing exactly the same information in precisely the same fashion. This is evidenced by one of Bartlett's experiments in which he found that individuals manipulated and retold a story they heard by applying their own unique interpretation and culture. It is also important to note that the more schemata one has, the better one can predict future behaviors [5]. Experienced drivers, for example, can drive any car, be it automatic or manual, better than novice drivers, because experienced drivers possess much more refined networks of schemata associated with driving. Schema theory would thus appear to be a convenient vehicle for explaining designers' existing internal models for designing products. In relation to design students, whenever they are given the task of creating a new product, their existing knowledge, or schemata, related to product creation will be activated to guide the new product design. Designers may select only relevant information or schemata related to the product, as they may deem appropriate from their own perspective, understanding, interpretation and culture. In relation to the present research, similar to the example of drivers, it can also be inferred that young designers or design students are likely to have fewer schemata than design experts or experienced designers, thus limiting their ability to design more successful products.

\subsection{Mental Models}

The literature suggests that mental models are similar to the concept of schemata [2] in the sense that people use existing knowledge stored in the brain to interact or react with objects and events [6]. Design students may have existing knowledge relevant to user testing, statistical analyses, and interpretation to help them in making decisions for designing products.

Mental models are not necessarily accurate; they are usually incomplete [7-8]. For instance, an individual with an accurate mental model of how an elevator works will understand that they only need to press the button once and wait, while people with an inaccurate or incorrect mental model might keep pressing the button until the lift doors open. This also suggests that mental models are based on individuals' personal experiences, beliefs and knowledge. Thus, everyone's experiences differ from everyone else's, another criterion similar to Schema Theory. For instance, designers are likely to have some knowledge, or even to possess complete mental models, of sketching and drawing using an AUTOCAD drawing tool, whereas lawyers, who have little or no knowledge of sketching and drawing, would not. In contrast, a designer may have no knowledge of what legal proceedings in court are all about unless they have some experience of attending one. However, knowledge and experience really depend on the nature and task and the way individuals interact with their environment [9]. Individuals' experience of grocery shopping is another example of such interactions. People usually know where to find bread and milk on the shelves regardless of which shops they go to; they can also search the signage provided in a shop. This is because the mental model of shopping for bread and milk is already stored in their minds. By contrast, the process of buying or renting a house may differ according to individuals' experiences, such as when dealing with fussy landlords or agents. With respect to this research, design students coming from different cultural and educational backgrounds as well as varying personal experiences may have different mental models or no knowledge of data collection, analysis or even what data sampling should be applied when designing new products. Therefore, their understanding, perception and acceptance level of new information or knowledge will differ. Mental models provide another valuable guideline for this present research.

\subsection{Cognitive Complexity Theory}

A second model related to designing user interface is Cognitive Complexity Theory (CCT) introduced by Kieras and Polson [10] and used in Human-Computer Interaction (HCI) in the mid-1980s, also in the era of command-based and menu-driven interfaces. While GOMS aimed at the structure and content of the knowledge, CCT represents the amount of knowledge users need to successfully complete their tasks. That knowledge is represented by a set of system rules. In that sense, CCT may be regarded as an extension of GOMS [11]. Elaborating further, The GOMS framework proposed by Card, Moran and Newell $(23,24)$ for user interface design comprises a set of procedures including goals, operators, methods and selection rules used to predict the efficiency of a computer system or comparing two or more systems by calculating the time it will take for a user to complete a given task [25].

The main concern of CCT is to ensure that a new computer system is 'easy to learn' and 'easy to use' [11]. CCT suggests providing users with procedural knowledge or 'how-to' knowledge [12] when using a tool to execute a task. One could thus offer several techniques for collecting data, leaving it to the user to 
choose the best technique for the particular product design context. Once a technique has been selected, the user should then be able to follow a step-by-step procedure; for example, to create a survey, taking them through the sub-tasks of defining a study, deciding upon the sample size, defining demographic questions, entering a series of questions, saving and running the study with potential respondents.

The procedural knowledge is therefore useful for novices. To the extent that several data collection methods are offered in a single tool, this renders the tool very flexible. It would enable users to compare results obtained through different data-collection and analysis techniques. Nevertheless, flexibility would also increase the amount of learning for novices to use the application effectively and efficiently. However, if a flexible application offers too many ways to complete tasks, that could prove too complex for novices with no knowledge about user testing and data analysis. The preliminary data gathered in our earlier investigations [13], showed clearly that design students had no working knowledge of statistics and hence no recollection of the steps and actions necessary for calculating, for example, the arithmetic mean or the median of a dataset. It therefore seems essential to provide adequate step-by-step information in the proposed tool to help them comprehend and eventually anticipate the steps needed when analyzing data statistically. Hence, this study follows CCT in the sense that it is essential to provide procedural knowledge or step-by-step instruction as highlighted in Scripts for a design student to accomplish a task in the proposed tool.

\subsection{Cognitive Theory of Multimedia Learning}

CTML [14] promotes the use of multimedia elements such as graphics, words, sounds, animation, video and gesture to foster learning. Among others, CTML suggests that people possess active processing capacity. This implies that learners will attempt to make sense of information when they pay attention to the relevant material by selecting, organizing and integrating it with their prior knowledge [14]-[16].

While there is some evidence to support the claim that presenting information in several techniques, such as the use of graphics or other elements, aids learning [17], other research suggests that this is not normally the case. For example, [18] carried out an experiment to investigate the validity of CTML specifically on the multimedia, spatial contiguity and coherence principles to facilitate learning by adding external graphic representations on paper-based and electronic learning materials among first-year students at a university. In CTML, multimedia principle focuses on the use of multimedia elements such as graphic, text, video and animation to facilitate learning, spatial contiguity principle emphasizes placing words and pictures on the same page/screen, and coherence principle highlights the need to exclude extraneous sounds, words and pictures to facilitate learning [19]. The study took special care in producing the graphical representation for both printed and animation materials by consulting at least 20 fourth-year students to find the best graphics. The materials given were considered to be difficult and new to the first-year students because they had no prior knowledge of the materials. They were given a pre-test to determine their prior knowledge, training with the relevant materials, and post-test questions for retention and transfer tests. Students learned with no graphics representation; with illustrations that were not spatially integrated; and with animations and sound but no narration, performed better. The study concluded that instructional designers could not simply apply CTML in designing instructional materials. However, this study suggests that instructional designers need to take extra care when choosing any graphical representation for a learning material relevant to individuals' differences. This was a crucial issue that was not addressed in this experiment and could lead to different results. This finding appears comparable to Cook [20] in the sense that suitable design and consideration between different learners need to be taken into account due to different prior knowledge, experience, skills and preference among learners.

\subsection{Cognitive Load Theory (CLT)}

Another model relevant to this research is known as Cognitive Load Theory (CLT), proposed by Sweller and his colleagues in 1980s. CLT [21] suggests that a major contributor to cognitive load is the quantity of elements that need to be attended to by learners. "Elements" means the content of information presented to an individual [21]. Complex information, such as mathematical calculations, can be difficult to learn-especially for design students who are not accustomed to rely on numbers in any way, as the preliminary data showed. Chunking information into elements or smaller sections is recommended to promote learning considering the lack of skills and knowledge of user testing among design students. Hence, the tool should be organized into several sections.

CLT was selected as the most relevant theory to guide the design and development of this tool due to several reasons with respect to design students' prior knowledge to run user test and perform statistical analysis. This theory provides useful guidelines to be considered. Firstly, it provides a simple tool that allows design students to easily understand and appreciate the tool. Secondly, designing a tool in such a way that it can be divided into smaller sections, frees up more space in their working memory to process and use the tool effectively. Thirdly, using different instructional techniques to present the information in the new tool; in this 
case, visual techniques for data collection and analysis, are highly relevant to designers generally, and design students particularly.

This section summarizes briefly the theoretical frameworks underpinning this research. Considering the limited knowledge of user testing and statistical analysis among design students, it is, therefore, necessary to design a simple and easy-to-use software tool for data collection and analysis, presented in different instructional techniques and smaller sections to foster learning. The following section describes the methods used for conducting this research.

\section{METHODS}

Paper prototypes of DACADE were prepared and evaluated in two formative usability tests to ensure that DACADE would not contain any usability flaws [13]. The prototypes were divided into four modules with four tasks, namely (1) designing a new study, (2) editing an existing study, (3) collecting data (i.e. running the study) and (4) conducting simple descriptive statistical analyses. The prototypes were evaluated iteratively with 11 design students at one design institution in the formative usability tests to satisfy the pre-determined usability goals. Based on the results in the first usability test; a tutorial was added and tested in the second usability test to aid design students' DACADE usage, as described in our earlier published work [13]. Upon implementation, a User Acceptance Test was conducted with 13 new participants to determine the level of user satisfaction, perceived usability and aesthetic appeal of DACADE among design students [22]. Results indicated that, despite the presence of the tutorial, the design students tested were still unable to grasp the necessary understanding and acquire the essential skill of collecting and analyzing data systematically. Based on the theories reviewed earlier, this study revealed several theoretical implications discovered during the design, implementation and evaluation of DACADE that could be beneficial for future research as briefly discussed in the next section.

\section{THEORETICAL IMPLICATIONS}

\subsection{Transfer of Learning}

This study followed the relevant guidelines provided by the theoretical frameworks discussed earlier. For example, dividing the task into the sections of New Study, Edit Study, Collect Data, and Run Analyses as recommended by CLT. Secondly, the study followed the principle of CCT, where the tasks were organized in steps, enabling users to simply follow the prompts in completing tasks. Nonetheless, it still seems insufficient for the design students to be able to grasp the gist of using DACADE and they did not perform well in the task. One possible reason for this could be that not enough attention was paid to the given tool and tasks. The findings suggest that the participants in the earlier usability studies [13], ]22] did not know or grasp the notion of collecting data from several consumers prior to deciding on a particular design. Taking shopping for a mobile phone as an example that participants would be likely to have experienced, one would investigate several plan and phone options in different physical and online shops, looking for good deals before settling on a decision. That example suggests that they actually would have some existing knowledge of sampling and comparing different possible solutions. This would indicate that they do understand the idea of data, but that they did not manage to transfer that knowledge to the present context. That is, participants appeared to have neglected to activate the relevant mental model enabling them to transfer their knowledge to a different type of problem. This problem of transfer has not been addressed by the theories reviewed in this study.

\subsection{Appropriateness}

The use of bananas as a graphical representation in our earlier study demonstrating arithmetical central tendencies was not ideal for the design student population [13]. It appeared that they simply focused on the salient features of the object and interpreted that as having sexual connotations, rather than recognizing them as representing the underlying meaning of descriptive statistics. The extent to which the apparent inappropriateness of the images initially selected may have affected participants' performance cannot be determined post hoc, but it may have played an important role. No theories were found that discussed the appropriateness of symbols selected to support the tasks and the audience.

\subsection{Motivation}

Another important finding of this research is that design students were hesitating to read the tutorial and the tasks, basically saying that they preferred illustrations, animations, and anything that would be more entertaining than text. Indeed, it took the researcher several attempts to encourage them to read before they would do it. Even so, several issues raised suggested that they did not pay as close attention to the 
explanations, examples, and even exercises as they needed so as successfully to complete all of the tasks in the tutorial as well as when using the tool. This suggests that learners in general, and design students in particular, at least in the present situation, need to be extrinsically motivated to learn. This important issue is not addressed in any of the learning-related theories reviewed in this paper.

\section{CONCLUSION}

This paper revealed several important theoretical implications related to learning theories in the process of developing DACADE. The implications related to the transfer of learning, the appropriateness of graphics used in a software tool, and user motivation in a learning environment. It is hoped that the implications discussed in this paper could serve as a as a guideline for future research in user-interface design as well as to foster learning.

\section{ACKNOWLEDGEMENTS}

This research was funded by International Islamic University Malaysia. We would like to thank design students and design lecturers at the School of Design, Swinburne University of Technology Australia who have volunteered to participate in this research.

\section{REFERENCES}

[1] Poirson, E., Petiot, J.-F., \& Richard, F. "A method for perceptual evaluation of products by naive subjects: Application to car engine sounds," International Journal of Industrial Ergonomics, 40(5), pp. 504-516, 2010.

[2] Bartlett, F. C. "Remembering: A study in experimental and social psychology," Great Britain: University Press, Cambridge, 1932.

[3] Jiang, J., Xu, G., \& Zhou, Z. “A teaching model based on Schema Theory in data mining curriculum,” Proceedings of the International Conference on Computer Science and Software Engineering, Wuhan, Hubei, 2008.

[4] Nash, K. "Mental Schema Accuracy: Investigating the impact of schemas on human performance and technology usability," Doctor of Philosophy thesis, Mississippi State University, Mississippi, 2012.

[5] Zhao, X., \& Zhu, L. "Schema Theory and college english reading teaching," English Language Teaching, 5(11), 2012.

[6] Johnson-Laird, P. N. "Mental Models: Towards a cognitive science of language, inference and consciousness," Cambridge: Cambridge University Press, 1983.

[7] Norman, D. "Some observations on mentai modeis," In D. Gentner \& A. L. Stevens (Eds.), "Mental models," 1983.

[8] Staggers, N., \& Norcio, A. F. "Mental models: concepts for human-computer interaction research," International Journal of Man-machine studies, 38(4), pp. 587-605, 1993.

[9] Erasmus, A. C., Bishoff, E., \& Rousseau, G. "The potential of using Script Theory in consumer behaviour research,” Journal of Family Ecology and Consumer Sciences, 30(1), 2002.

[10] Kieras, D., \& Polson, P. G. "An approach to the formal analysis of user complexity," International Journal of Manmachine studies, 22(4), pp. 365-394, 1985.

[11] Bovair, S., Kieras, D. E., \& Polson, P. G. "The acquisition and performance of text-editing skill: A cognitive complexity analysis," Human-Computer Interaction, 5(1), pp. 1-48, 1990.

[12] Polson, P. G., Bovair, S., \& Kieras, D. "Transfer between text editors," Proceedings of ACM SIGCHI Bulletin, 1987.

[13] Sheikh Abdul Aziz, M. Lindgaard, G., \& Whitfield, T. W. "Evaluating a visual tool for systematic data collection and analysis for design students," ARPN Journal of Engineering and Applied Sciences, 10(23), pp. 17853-17862, 2015.

[14] Mayer, R. E. "Cognitive theory of multimedia learning," The Cambridge handbook of multimedia learning, pp. 3148, 2005.

[15] Mayer, R. E., \& Moreno, R. "A cognitive theory of multimedia learning: Implications for design principles," Journal of Educational Psychology, 91(2), pp. 358-368, 1988.

[16] Sorden, S. "The cognitive theory of multimedia learning," Handbook of educational theories, Charlotte, NC: Information Age Publishing, 2012.

[17] Mayer, R. E., Bove, W., Bryman, A., Mars, R., \& Tapangco, L. "When less is more: Meaningful learning from visual and verbal summaries of science textbook lessons," Journal of educational psychology, 88(1), 64, 1996.

[18] Westelinck, K. D., Valcke, M., De Craene, B., \& Kirschner, P. "Multimedia learning in social sciences: Limitations of external graphical representations," Computers in Human Behavior, 21(4), pp. 555-573, 2005.

[19] Cooper, G. "Research into cognitive load theory and instructional design at UNSW," http://webmedia.unmc.edu/leis/birk/CooperCogLoad.pdf, 1988.

[20] Cook, M. P. "Visual representations in science education: The influence of prior knowledge and cognitive load theory on instructional design principles, "Science education, 90(6), pp. 1073-1091, 2006.

[21] Sweller, J. "Cognitive load during problem solving: Effects on learning," Cognitive science, 12(2), pp. 257-285, 1988. 
[22] Sheikh Abdul Aziz, M., Lindgaard, G., \& Whitfield, T. W. A. "The Design and Usability Testing of DACADE- A Tool Supporting Systematic Data Collection and Analysis for Design Students," Proceedings of INTERACT Springer Berlin Heidelberg, Cape Town, South Africa. Vol. 8117, pp. 487- 494, 2013.

[23] Card, S. K., Moran, T. P., \& Newell, A. "Computer Text Editing: An information- processing analysis of a routine cognitive skill, "Cognitive psychology, (12), pp. 32- 74, 1980.

[24] Card, S. K., Newell, A., \& Moran, T. P. The Psychology of Human-Computer Interaction: L. Erlbaum Associates Inc, 1983.

[25] Schrepp, M. "GOMS analysis as a tool to investigate the usability of web units for disabled users," Universal Access in the Information Society, 9(1), pp. 77-86X, 2010.

\section{BIOGRAPHIES OF AUTHORS}

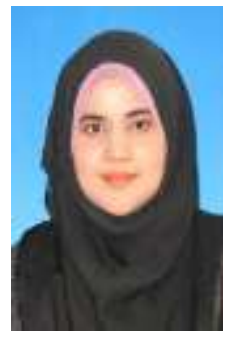

Madihah Sheikh Abdul Aziz is an Assistant Professor of Human Computer Interaction at the Faculty of ICT, International Islamic University Malaysia. She completed her $\mathrm{PhD}$ research at the School of Health, Art and Design, Swinburne University of Technology, Melbourne, Australia. Her research interests are in the area of Interaction Design, Usability Testing, User Experience, Game-based learning and Digital Media Design.

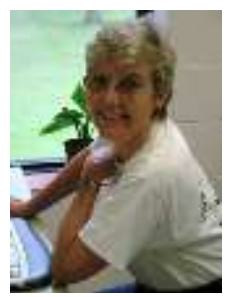

Gitte Lindgaard is a distinguished Research Professor at Carleton University in Ottawa, Canada, and a Professor in strategic Design at Swinburne University of Technology in Melbourne, Australia. Her research interests include aesthetics, cognition, and emotion in computing, and human decision making. She has published over 240 refereed papers, books, and book chapters.

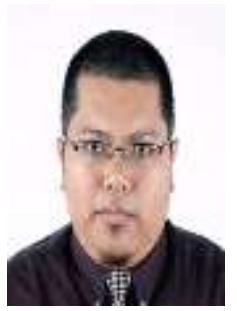

Mohd Syarqawy Hamzah is an Assistant Professor at the Faculty of ICT, International Islamic University Malaysia. He completed his PhD research at the School of Computer Science, Nottingham University, United Kingdom. His research interests are in the area of Game-based learning and User Experience.

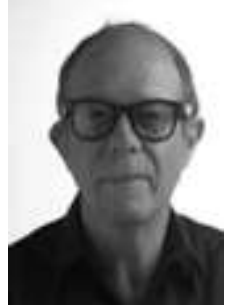

Allan Whitfield is a Research Professor at the School of Health, Arts and Design, Swinburne University of Technology, Melbourne, Australia. He has published extensively in the psychology and design literature. 